\title{
Ensino Médio noturno: democratização e diversidade
}

\section{Evening High School: democratization and diversity}

\author{
Sandra Zákia Sousa ${ }^{*}$ \\ Romualdo Portela de Oliveira**
}

\begin{abstract}
RESUMO
O propósito do texto é divulgar resultados de pesquisa nacional, desenvolvida em oito estados de todas as regiões do país (MS, MG, PA, PB, RN, RS, SC e SP), acerca do ensino médio noturno. O material coletado para o estudo, por meio de aproximadamente dez mil entrevistas com professores, alunos e diretores de escolas que ofereciam ensino médio noturno, permitiu analisar ações em implementação nessas escolas, visando oferecer subsídios para a formulação e implementação de políticas educacionais para o ensino médio, contemplando especificidades do noturno.

Palavras-chave: ensino médio; ensino noturno; política educacional.
\end{abstract}

\begin{abstract}
The purpose of this paper is to release results of a national research developed in eight Brazilian states of all regions (MS, MG, PA, PB, RN, RS, SC, SP), about evening high school. The material collected for the study, roughly 10,000 interviews with teachers, students and principals of schools that offered evening high school. They were allowed to analyze actions of these schools, and with this, it is possible to rethink the formulation of educational policies at high school levels with the specific characteristics of the evening school.

Key words: high school; evening school; educational policy.

*** Faculdade de Educação da USP. E-mail: sanzakia@usp.br.

***Faculdade de Educação da USP. E-mail: romualdo@usp.br.
\end{abstract}


Neste texto, são apresentados alguns resultados do estudo intitulado Ensino Médio Noturno: registro e análise de experiências, realizado no ano de $2003^{1}$, que teve por finalidade levantar subsídios para a formulação e implementação de políticas educacionais, contemplando eventuais especificidades desta etapa e turno de ensino.

Para tanto, buscou-se registrar e analisar experiências no Ensino Médio noturno, em uma amostra intencional de 80 escolas, distribuídas em oito unidades federadas, quais sejam: Mato Grosso do Sul, Minas Gerais, Pará, Paraíba, Rio Grande do Norte, Rio Grande do Sul, Santa Catarina e São Paulo. Essa análise visou identificar condicionantes administrativos, legais, pedagógicos, culturais e outros que contribuem para o sucesso ou eventuais limitações das experiências desenvolvidas pelas escolas pesquisadas, bem como seu potencial de indicar intervenções possíveis para o universo de escolas que oferecem ensino médio noturno.

Procurou-se desvendar momentos do movimento vivido por escolas que oferecem ensino médio noturno, a partir da perspectiva de democratização do ensino, em suas dimensões de acesso e permanência na escola, com um ensino de qualidade. Ainda, assumiu-se como princípio para análise das experiências escolares a busca de tendências comuns, propostas e/ou práticas recorrentes, mas, sobretudo de especificidades e diversidades dos contextos estudados, visando apreender condições e/ou fatores capazes de contribuir para a melhoria da qualidade de ensino.

Diante dos limites deste texto, optou-se por destacar considerações oriundas da pesquisa que tratam, respectivamente, dos alunos do ensino médio noturno e das finalidades, controvérsias e desafios que se apresentam para essa etapa e turno de ensino.

\section{Alunos: diferentes características, diferentes expectativas}

Alguns resultados da pesquisa trazem subsídios para os educadores refletirem acerca de especificidades e características do alunado e suas possíveis consequências na organização do trabalho escolar, bem como para o enfrentamento do antigo dilema entre escola média profissionalizante ou de educação geral/propedêutica.

Buscou-se conhecer especificidades do alunado que vem freqüentando o Ensino Médio noturno, visando iluminar alternativas de intervenção nos sis-

$1 \mathrm{O}$ estudo foi realizado em atendimento à demanda da Secretaria de Ensino Médio e Tecnológico do Ministério da Educação (SEMTEC/MEC). Esta Secretaria, em 2004, tornou-se Departamento de Políticas de Ensino Médio da Secretaria de Educação Básica, em decorrência de reorganização do organograma do MEC. Em seu desenvolvimento, contou-se com a participação de pós-graduandos da FEUSP e professores de universidades de cada um dos estados envolvidos na pesquisa. 
temas educacionais, que possibilitem o aprimoramento do atendimento a esta clientela, como especial compromisso de melhorar os índices de conclusão, com qualidade, dos que iniciam o curso, assim como traçar alternativas de ampliação do acesso.

As informações foram coletadas por meio de questionários, respondidos pelos alunos, bem como por seus professores, coordenadores e diretores, abrangendo aproximadamente dez mil entrevistados. Segue-se uma descrição sucinta das informações levantadas sobre os alunos, que trazem, como principal evidência, a necessidade de estarmos atentos para as diferentes populações que vêm buscando o Ensino Médio noturno.

Entre as diferenciações que se evidenciaram acerca da clientela do ensino noturno, a primeira delas é percebida entre os alunos que têm no estudo sua principal atividade/responsabilidade e aqueles que, antes de serem estudantes, são trabalhadores ou buscam, de imediato, ingressar no mercado de trabalho. Dessa diferenciação, não deveria decorrer qualquer interpretação que indique uma valorização diferente, por parte dos alunos, da escolarização, mas sim especificidades nas relações estabelecidas com a escola.

No entanto, o que se notou, em alguns relatos de profissionais da escola, é que eventuais menções a trabalhadores-estudantes são feitas no sentido de apontar a necessidade de compreensão dos vínculos frágeis que estes usualmente estabelecem com o processo de escolarização. Essa interpretação tende a gerar, por parte da equipe escolar, propostas e práticas de ensino "menos exigentes", embora estas se apresentem em nome do compromisso com a permanência desses alunos na escola.

Ilustram esta afirmação os casos nos quais é facilitada a entrada dos alunos, aceitando-se seus atrasos, pois sua jornada de trabalho atravessa o horário da primeira aula do período. Com isso, o aluno deixa de ter contato com os conteúdos desenvolvidos naquela aula. Parece ocorrer uma naturalização dessa realidade. Também, verificaram-se experiências em que a primeira aula do período destina-se a atividades que possam ser realizadas fora da escola. Iniciativas desta natureza, embora tenham origem no relevante propósito de minorar ou evitar a evasão escolar, podem vir a resultar em menor compromisso com a qualidade do ensino ofertado aos trabalhadores-estudantes.

Tal perspectiva implica, no limite, em um confronto com a representação existente no interior da escola, dominante entre seus profissionais, de que sua função primordial é propedêutica, desvalorizando-se iniciativas que se voltem à profissionalização. Nesses casos, tais iniciativas são entendidas como "de menor valor educacional" em função dos "limites da clientela". Remete, portanto, à necessidade de superação da dicotomia formação geral X formação profissional. 
No entanto, a postura que se evidenciou, de modo dominante, no tratamento do aluno que freqüenta o noturno foi a desconsideração de especificidades de sua realidade de vida e trabalho. Embora, nos registros obtidos nas escolas, menções tenham sido feitas aos diferentes perfis de alunos que freqüentam o noturno, estes parecem não estar sendo considerados nos planos, programas e ações escolares. Foram raras as iniciativas de se buscar um diagnóstico mais preciso sobre características, expectativas e aspirações dos alunos, que viessem a embasar decisões relativas à organização e funcionamento do trabalho.

Outra característica que diferencia os alunos do Ensino Médio noturno é a trajetória escolar; ou seja, parte deles está dando continuidade aos seus estudos, sem interrupção - mesmo que com reprovações anteriores -, e outros estão retornando à escola, que foi por eles abandonada, em diferentes momentos do processo de escolarização. Certamente, essas histórias têm reflexos na interação escolar atual; no entanto, parecem não estar sendo consideradas pelos profissionais da educação na organização do trabalho escolar.

Ainda, como elemento de diferenciação dos alunos, tem-se suas expectativas após a conclusão do curso. Muitos manifestaram o desejo de dar continuidade aos estudos, principalmente em nível superior. Outros declararam pretender continuar trabalhando ou iniciar trabalho. Tais intenções, evidentementes, são colocadas em função das possibilidades de vida e de trabalho em que se encontram os alunos. No entanto, pode-se supor que a permanência ou o retorno aos estudos traduz uma valorização da escolarização, na busca do que a maioria define como "um futuro melhor".

Há que se observar que, algumas vezes, as propostas escolares tendem a se conformar às suposições sobre o destino dos alunos após o Ensino Médio. Nesse sentido, alerta-se para o risco de que o destino profissional ou acadêmico do aluno, presumido pelo professor e equipe escolar, seja tomado como um critério para a organização da escola ou sua organização curricular, limitando escolhas futuras.

A existência do aluno e do trabalhador-estudante, do aluno que percorre a trajetória de escolarização sem interrupções e daquele que retorna à escola após períodos de abandono, sugere a necessidade de se contemplar a possibilidade de oferta diversificada de ensino, no sentido de se criarem ambientes escolares capazes de acolher os diferentes públicos que vêm demandando o Ensino Médio noturno e potencializar suas escolhas futuras. 
De qualquer modo, a escola, para todos os alunos, parece constituir, para além de um espaço de ensino, um espaço cultural e social. Na maioria das vezes, é o único e/ou principal espaço público de acesso à informação e à cultura sistematizada. As informações registradas de mais de 8 mil alunos do Ensino Médio, ouvidos pela pesquisa, evidenciam o estado de isolamento cultural em que vive a maioria, cumprindo a escola, mesmo com suas precariedades, importante papel formativo.

As informações sobre características e especificidades do aluno do Ensino Médio noturno, obtidas com a pesquisa aqui mencionada, devem ser cotejadas com indicações de outros estudos já divulgados, entre os quais citamos alguns, destacando contribuições que trazem para a nossa reflexão.

A pesquisa de Dalila Andrade de Oliveira (1994), realizada antes da promulgação da Lei de Diretrizes e Bases da Educação Nacional (LDB), Lei n. 9.394/96, aponta que a expressão "aluno trabalhador" carrega uma diversidade de características, decorrente da diversidade de experiências vivenciadas na trajetória escolar pelo aluno, isto é, do significado da escola para ele.

Segundo a autora, foi possível identificar dois subgrupos de alunos trabalhadores, com aspectos que os aproximam e o diferenciam:

Em relação aos aspectos comuns, posso destacar a situação de estudos e de trabalho. (...) todos os entrevistados trabalham e enfrentam dificuldades para conciliar estas duas atividades. Contudo, existem peculiaridades que marcam suas trajetórias e que não podem ser ocultadas através de generalizações, considerando apenas o fato de os entrevistados pertencerem às camadas populares. (OLIVEIRA, 1994, p. 95)

Diz a autora que a escola, para um dos subgrupos,

(...) representa um espaço social necessário à sua atualização cultural e socialização. É o espaço onde têm a oportunidade de se relacionarem com pessoas do seu meio social e de tentar planejar um outro modo de vida. A atividade profissional exercida parece ser um fator de motivação para a freqüência à escola, entendida como local de socialização e descanso da rotina. Não se observa entre esses estudantes perspectivas de continuidade dos estudos. (OLIVEIRA, 1994, p. 96) 
Para o outro subgrupo, a escola representa

a possibilidade de melhorar de vida. Alguns vislumbram a continuidade dos estudos após o término do Ensino Médio e os demais procuram no diploma a possibilidade de melhorar a sua situação no emprego. A clareza dessas expectativas se desdobra em estratégias mais concretas para que os estudantes persigam seus objetivos e tenham maior motivação para a permanência na escola. (OLIVEIRA, 1994, p.96)

Outra pesquisa desenvolvida com alunos do Ensino Médio noturno, tendo como um dos objetivos identificar as demandas dos alunos desse turno, destaca que a maioria dos alunos do noturno é jovem; no entanto, a escola tende a esperar dos mesmos um comportamento adulto. Ou seja: "são alunos trabalhadores, mas são jovens trabalhadores (...) por parte da escola espera-se um aluno maduro, responsável, marcado, não pela juventude, mas pelo mundo do trabalho" (SILVA, 2000, p. 51).

Esses jovens, por sua vez, expressam o desejo de não serem vistos como alunos trabalhadores cansados, mas gostariam de regras e exigências claras. $\mathrm{O}$ cansaço é atribuído, pelos alunos, mais à monotonia das aulas e à falta de espaço para participação do que à fadiga decorrente do trabalho. Expressam, ainda, o desejo de que o Ensino Médio proporcionasse condições para se entrar em um curso superior. Mesmo aqueles que pensam em fazer um curso profissionalizante afirmam que é para conseguir um emprego e ter condições financeiras para fazer um curso superior.

Há, também, nos alunos um sentimento de inferioridade (é constante a comparação com o turno diurno) e a noção de que tudo conspira contra seus objetivos: escola pior; professor menos motivado; política pública equivocada ou ausente. Criticam severamente a não-reprovação, alegando, entre outras razões, que faz parte dos objetivos implícitos do governo que eles concluam o curso sem o devido preparo e condições de passar pelo vestibular.

Outra pesquisa, realizada com alunos do Ensino Superior noturno, coordenada por Marília Sposito, também dá pistas para compreender quem é o estudante trabalhador, e traz evidências que se aproximam das já destacadas neste texto. Da mesma forma que os alunos do Ensino Médio, a maior parte dos alunos do Ensino Superior noturno começou a trabalhar enquanto terminava o Ensino Fundamental ou iniciava o Médio. Procuram na escola a possibilidade de melhoria de vida, isto é, 
[...] a importância dada à escola como pré-requisito para empregos mais bem-remunerados e de maior prestígio social perpassa os relatos de quase todos os alunos sobre a trajetória no mercado de trabalho, às vezes implícita, outras explicitamente. (SPOITO, 1989, p. 61)

Essa importância do curso superior tende a ser percebida pelos alunos já no momento em que estão no curso, ou seja:

[...] ao compararmos as ocupações exercidas na época em que começaram a trabalhar com as ocupações atuais, é possível conferir que a freqüência à escola, entre outros fatores, possibilitou certa "melhora" na escala ocupacional para aqueles que nela ocupavam posições menos valorizadas. É evidente que este papel positivo atribuído à escolaridade apareceu em quase todos os depoimentos. (SPOSITO, 1989, p. 60)

O perfil desse aluno, em linhas gerais, é: situações de trabalho, geralmente, são de rotina; falta de perspectiva, marcada pelo exercício da submissão; e a condição de estudante determinada pela sua condição de trabalhador, porém com pouca percepção disso.

A maior parte dos alunos mostrou-se muito satisfeita com o ingresso no curso superior; no entanto, este foi realizado de modo a não "atrapalhar" o trabalho. Em outros casos, para quem já trabalhava na área, o Ensino Superior era visto como complementar.

Destacam-se, a seguir, dois registros de Sposito (1989) que, embora direcionados ao trabalhador-estudante de cursos superiores, certamente trazem pistas para compreendermos a relação que uma parte dos alunos do Ensino Médio noturno estabelece com a escola:

Discriminados economicamente, sofrendo as desigualdades do sistema escolar, esses alunos acreditam que a posse do 'saber', ainda considerado como algo obscuro e até mágico, lhes daria condições de melhor enfrentamento e talvez de superação de sua condição social. (SPOSITO, 1989, p. 102) 
A faculdade é para o trabalhador-estudante um momento importante de reapropriação de um saber gradativamente expropriado ao longo da escolaridade e permite uma relação diferente com o processo de conhecimento e com a sua prática no mundo do trabalho (SPOSITO, 1989, p. 115).

As indicações trazidas pelas pesquisas aqui mencionadas, acerca de especificidades e características dos alunos que freqüentam o turno escolar noturno, podem suscitar diversos focos de análise e reflexão, pelos educadores envolvidos nas diferentes instâncias dos sistemas de ensino - desde os órgãos centrais até as unidades escolares.

Entre estes, talvez um aspecto inicial a ser debatido pelos que atuam no Ensino Médio noturno se refere à oportunidade e à pertinência de se delinearem alternativas diversificadas de atendimento escolar, considerando características e expectativas diferenciadas do alunado que demanda a escola, como condição para a garantia de seu direito à educação básica.

Nessa direção, um caminho a ser explorado é a criação e/ou dinamização de espaços que dêem voz aos alunos do noturno, para que eles próprios contribuam com propostas de planejamento escolar.

\section{Ensino Médio: finalidades, controvérsias e desafios}

A configuração geral do sistema de ensino reserva funções específicas para o Ensino Médio. Dessa forma, mais do que um debate isolado sobre seu sentido, parece-nos necessário pensar qual o seu sentido no sistema nacional de ensino. No Brasil, o Ensino Médio, historicamente, esteve organizado na perspectiva de preparar para o Ensino Superior, destinado às elites e, nessa perspectiva, com oferta limitada de vagas. A expansão das oportunidades de escolarização, a partir de 1930, fez com que uma outra demanda emergisse, a do Ensino Médio vinculado à profissionalização, entendida como preparação para o ingresso no mercado de trabalho, uma vez que o acesso ao ensino superior permanecia limitado.

O impasse histórico do Ensino Médio consistiu na tensão entre a natureza propedêutica original, de um ensino destinado às elites, de um lado, e a necessária 
articulação com a preparação para o trabalho, decorrente da sua expansão para setores das classes trabalhadoras - neste caso revestida com a característica de educação "para os pobres"2.

A Lei n. 5.692, de 1971, enfrentou essa tensão estabelecendo a profissionalização obrigatória. Naquela ocasião, a motivação da reforma era também diminuir a pressão que os egressos do Ensino Médio exerciam por mais vagas nas universidades, ancorada na suposta demanda do mercado de trabalho por técnicos e em dada leitura da teoria do capital humano, segundo a qual a profissionalização do Ensino Médio estaria articulada com a perspectiva de impulsionar o desenvolvimento nacional. A política de profissionalização compulsória fracassou desde a sua concepção, seja pela impossibilidade estrutural de toda a rede de Ensino Médio tornar-se profissionalizante, seja pela impossibilidade econômica de inserir no mercado de trabalho todos os técnicos formados nesse novo modelo. Já em 1975, sofre alterações que buscaram minimizar seus efeitos e, em 1982, com a Lei n. 7.044, suprime-se seu ponto mais polêmico: a obrigatoriedade da profissionalização.

No entanto, uma política de tal impacto, que pretendeu apresentar um sentido para o Ensino Médio, deixou marcas. Bastaria dizer que, no período de 1972 a 1983, a matrícula, nessa etapa, mais que dobrou. Em 1972, eram 1,3 milhão os matriculados, e em 1983, 2,9 milhões. À formação geral, nem sempre percebida como necessária, juntou-se a idéia, nem sempre real, da possibilidade de inserção em um mercado de trabalho pronto a receber novos e mais trabalhadores, com supostas qualificações específicas.

A revogação da profissionalização compulsória não significou a emergência de um outro sentido para o Ensino Médio, mas sim o reconhecimento da impossibilidade de isso ser feito naquele momento. Uma nova hegemonia levaria alguns anos para se consolidar. Em artigo de referência que tomou o conjunto das publicações sobre o Ensino Médio nos Cadernos de Pesquisa, Dagmar Zibas (1992, p.58) registra que, desde o início dos anos 80, foi se estabelecendo entre pesquisadores e educadores a "compreensão do $2^{\circ}$ Grau como complemento indissociável do $1^{\circ} \mathrm{Grau}$; e a tese da formação para o trabalho dentro do $2^{\circ} \mathrm{Grau}$, entendida como formação para a cidadania".

Tal concepção vai se transformar em norma legal com a Lei de Diretrizes e Bases da Educação Nacional (LDB), Lei n. 9.394/96, em vigor. Dispõe essa lei que a educação básica será composta por três etapas: a Educação Infantil, o Ensino Fundamental e o Ensino Médio. Nessa perspectiva, entendendo o Ensino Médio como parte da formação geral, articula-se a antiga polaridade:

2 No artigo 129 da Constituição Federal de 1937, afirma-se: "O ensino pré-vocacional, destinado às classes menos favorecidas é, em matéria de educação (...)” (grifo nosso). 
propedêutico profissional. Dessa concepção decorre toda a reforma do Ensino Médio, que desvinculou a formação geral, potencialmente direito de todos, da formação profissional, opção ou exigência para a ocupação de determinados postos de trabalho.

Desde a promulgação da Constituição Federal de 1988, pretende-se a universalização do Ensino Médio no Brasil. O texto da CF foi alterado pela Emenda Constitucional n. 14/1996, que estabeleceu a "progressiva universalização do Ensino Médio gratuito" (inciso II do artigo 208). A formulação original foi retomada na LDB e define a "progressiva extensão da obrigatoriedade e gratuidade ao Ensino Médio" (inciso II do artigo $4^{\circ}$ ). Concretizando ainda mais essa perspectiva, o Plano Nacional de Educação estabeleceu, em 2001, o atendimento de $100 \%$ da demanda do Ensino Médio, no prazo de dez anos.

Essa mudança legal, que amplia o direito à educação para além do Ensino Fundamental, é produto de mudanças mais profundas na sociedade brasileira, a começar pela democratização política do país, que explicitou as lutas pela ampliação dos direitos de cidadania, entre eles, o direito à educação, objetivado no acesso ao Ensino Médio.

Os debates que precederam a LDB e fizeram avançar essa concepção foram realizados num contexto político e econômico mais definido do que aquele que se encerrou com a promulgação da Constituição Federal. As mudanças decorrentes da redemocratização de boa parte dos países pobres, da globalização da economia, das novas tecnologias e da ampliação do acesso às informações em tempo real, marcaram o cenário mundial e do Brasil, e radicalizaram tendências mais conservadoras, reduzindo significativamente o avanço na conquista de direitos, que resultou, para o Ensino Médio, na alteração do texto constitucional.

Esse mesmo cenário mundial de crise econômica e política acirrou a competição entre as empresas e instituições, entre nações, e entre todos e cada um, fazendo crescer de modo impressionante a valorização da escola e da escolarização no Brasil. Cada vez mais o mercado de trabalho se retrai e cria exigências mais elevadas de escolarização para o ingresso em qualquer ocupação. Além disso, a permanência da população mais jovem na escola tem o potencial de contribuir para retardar seu ingresso no mercado de trabalho, minimizando, ainda que temporariamente, os efeitos do desemprego sobre os jovens e suas famílias.

No interior dos sistemas de ensino, um conjunto de medidas, programas e políticas governamentais - como a correção do fluxo escolar; a construção 
de escolas nas regiões mais carentes (Projeto Nordeste e Fundescola); a LDB, que flexibilizou a organização do ensino, entre outras iniciativas - cumpriram importante papel na ampliação do acesso à escola e na permanência dos alunos vindos das camadas mais pobres da população, diga-se, a maioria dos brasileiros. A última década assistiu ainda à realização de programas não-governamentais, por organizações da sociedade civil, em apoio a programas oficiais, como o desenvolvimento de ações de formação de professores ou de produção de material de apoio às escolas, também a atuação em áreas desassistidas pela política governamental, como a alfabetização de jovens e adultos.

Daí, pode-se afirmar que a pressão pela ampliação de vagas no Ensino Médio é propiciada tanto pelo contexto econômico mais amplo quanto pela movimentação interna aos sistemas de ensino que, desde o final dos anos de 1990, vêm enfrentando, como nunca, a questão do acesso à escola para crianças e jovens, sobretudo aqueles na faixa entre 6 e 14 anos, período da escolarização obrigatória.

Entretanto, essas formulações legais se defrontam com diferentes expectativas de setores da população em relação ao Ensino Médio, que dificultam a formulação de uma alternativa única e inflexível; ou seja, a população que busca o Ensino Médio, pela sua diversidade, demanda uma articulação de políticas e programas que dêem conta de atender aos egressos do Ensino Fundamental, que o concluem na idade considerada "correta", para quem o Ensino Superior é uma perspectiva em termos de desejo, mas que não se contrapõe a uma certa profissionalização; e aos egressos do Ensino Fundamental ou de programas de educação de jovens e adultos que retornaram à escola, os quais, em sua quase totalidade, antes de serem estudantes são trabalhadores (mesmo que muitas vezes desempregados).

Responder a essas demandas diferenciadas e, ao mesmo tempo, manter seu caráter de formação geral é o desafio que o texto da LDB procura colocar. Nessa lei, nas disposições gerais, a educação básica "tem por finalidade desenvolver o educando, assegurar-lhe a formação comum indispensável para o exercício da cidadania e fornecer-lhe meios para progredir no trabalho e em estudos posteriores" (art. 22). Sobre isso, Carlos Roberto Jamil Cury (2002, p.16) destaca que "a qualidade básica não é privativa de nenhuma etapa e/ou modalidade" e, portanto, "o caráter indispensável, articulado à cidadania e ao trabalho, é próprio de toda a educação básica", reforçando a compreensão unificadora que a LDB confere a esse nível do ensino.

A mesma lei, no artigo 35, estabelece as seguintes finalidades para o Ensino Médio: 
I - a consolidação e o aprofundamento dos conhecimentos adquiridos no ensino fundamental, possibilitando o prosseguimento de estudos;

II - a preparação básica para o trabalho e a cidadania do educando, para continuar aprendendo, de modo a ser capaz de se adaptar com flexibilidade a novas condições de ocupação ou aperfeiçoamento posteriores;

III - o aprimoramento do educando como pessoa humana, incluindo a formação ética e o desenvolvimento da autonomia intelectual e do pensamento crítico;

IV - a compreensão dos fundamentos científico-tecnológicos dos processos produtivos, relacionando a teoria com a prática, no ensino de cada disciplina.

O que está expresso na LDB é a opção política pela formação geral, enfrentando, ainda que no papel, a indefinição histórica vivida por essa etapa da escolarização. Essa nova condição para o Ensino Médio representa um avanço, pois admitir que este é parte da educação básica significa abrir a perspectiva de incorporação à escola de grandes parcelas da população até então excluídas. Segundo Celso Beisiegel (2002, p.45), a explosiva ampliação da oferta de vagas no Ensino Médio pode remeter a críticas como as que ocorreram em relação ao Ensino Fundamental, ou seja, a perda de suposta qualidade. $\mathrm{O}$ autor defende que há aí uma nova qualidade, que é o acesso aberto a todos, e afirma que a qualificação dessa etapa da escolarização tem como pressuposto "a clara compreensão das implicações e a plena aceitação da legitimidade da presença dos jovens das classes populares no Ensino Médio". (BEISIEGEL, 2002, p. 45)

As Diretrizes Curriculares Nacionais para o Ensino Médio explicitam ainda mais as concepções emanadas da LDB. No Parecer n. 15/98, da Câmara de Educação Básica do Conselho Nacional de Educação, estão registrados os princípios da reforma do Ensino Médio. Valoriza-se o aprender contínuo de linguagens e tecnologias como suporte para o prosseguimento nos estudos, para o exercício pleno da cidadania e para a inserção no mundo do trabalho. O trabalho é tomado como organizador do currículo, "como forma de interação com a natureza e o mundo social". 
Nesse quadro, a formulação de políticas para o Ensino Médio enfrenta hoje o duplo desafio: expandir o número de vagas de modo a atender à parcela da população ainda excluída e delinear alternativas de articulação com uma perspectiva de educação profissional.

\section{Indicações relativas à política educacional para o Ensino Médio noturno}

Desde o início da pesquisa tinha-se clara a impossibilidade de adoção de qualquer perspectiva prescritiva, entre outras razões por se considerar a autonomia dos entes federados e as competências do governo nacional e dos governos subnacionais, definidas constitucionalmente, bem como as especificidades e desigualdades presentes no Ensino Médio noturno, no território nacional.

Assumiu-se, também, como ponto de partida do estudo, o dinamismo inerente ao processo de formulação de políticas, as quais se concretizam por meio de perspectivas, interações, decisões e práticas de muitos sujeitos, internos e externos aos governos, que representam projetos educacionais e sociais muitas vezes conflitantes entre si. Ou seja, da formulação de dada política à sua implementação são inúmeros e diversificados os seus condicionantes.

Assim, a pesquisa configurou-se como um estudo descritivo e analítico, de propostas e práticas direcionadas ao Ensino Médio noturno supostamente capazes de produzir um ensino de qualidade, tendo como foco a escola, espaço que seria privilegiado na apreensão de pistas para a formulação de políticas. Não se pretendeu traçar um quadro representativo das escolas brasileiras ou mesmo dos estados pesquisados.

Retomam-se, neste texto, algumas recomendações oriundas da pesquisa, ou seja, aquelas mais diretamente relacionadas aos aspectos tratados: os diferentes públicos que vêm demandando o Ensino Médio noturno e a identidade dessa etapa e turno de ensino. São elas: 


\section{Estabelecer políticas que tenham como alvo o planejamento da expansão do atendimento, levando-se em conta a diversidade dos alunos que buscam o Ensino Médio noturno.}

A demanda pelo Ensino Médio tem conhecido um crescimento significativo nos últimos anos, tendendo, ainda, a ampliar-se nos próximos. Como alternativa para atendê-la, os sistemas de ensino têm reservado papel especial ao ensino noturno, mesmo que nos últimos anos sua participação relativa na matrícula total tenha diminuído. Verificou-se na pesquisa que o acesso ao Ensino Médio noturno está condicionado ao desenho geral da organização física das redes; ou seja, em algumas localidades, por exemplo, não há oferta de Ensino Médio no diurno, fazendo com que a matrícula no noturno seja compulsória. Em outras, por ausência de vagas no ensino regular, as matrículas de alunos fora da faixa etária esperada para essa etapa da educação básica são encaminhadas diretamente à educação de jovens e adultos. Assim, a tendencial regularização do fluxo no ensino fundamental pode, como já está ocorrendo, criar maior capacidade de atendimento do Ensino Médio diurno.

\section{Definir fontes específicas de financiamento e linhas direcionadas para o Ensino Médio noturno.}

Por ocasião da redação final do relatório de pesquisa, observávamos que o crescimento da demanda agrava o problema da inexistência de fonte específica de financiamento para o Ensino Médio, tendo seus recursos comprimidos, em nível estadual, entre aqueles comprometidos com o ensino fundamental pelo Fundo de Manutenção e Desenvolvimento do Ensino Fundamental e Valorização do Magistério (FUNDEF) e os destinados às demais etapas e níveis educacionais, notadamente o superior. A recente aprovação do Fundo de Manutenção e Desenvolvimento da Educação Básica e Valorização do Magistério (FUNDEB) responde a essa necessidade, ainda que limitada pela ausência de aportes adicionais de recursos, sem os quais prenuncia-se mais uma redistribuição dos já alocados, explícita ou implicitamente, para o Ensino Médio. Complementarmente, sugere-se a alocação 
de recursos diretamente às unidades escolares, estabelecendo-se critérios explícitos e detalhados de financiamento, que contemplem as áreas que se quer atingir nas escolas, privilegiando-se ações coletivas, articuladas por objetivos comuns, nos moldes de programas como o Programa Dinheiro Direto na Escola.

\section{Fixar o professor na mesma escola, por um dado período.}

Entre os problemas enfrentados pelas escolas do Ensino Médio noturno está a grande rotatividade de professores. Os vínculos empregatícios precários, constatados em todas as redes de ensino pesquisadas, são apontados como fator determinante da rotatividade. Também, a atribuição de aulas, que permite aos professores com mais tempo na carreira escolherem as escolas e nelas, as disciplinas e turnos onde vão lecionar, além de remanejamentos solicitados por professores em qualquer momento do ano letivo, favorecem esse fenômeno. Sugere-se a exigência, em legislação específica, da fixação do professor, na mesma escola, por um dado período. A construção e implementação coletiva de um projeto político pedagógico pressupõe a constituição de uma equipe de trabalho, para o que o tempo de trabalho conjunto é condição fundamental.

\section{Incentivar a criação e/ou adequação de espaços físicos nas es- colas.}

Recomendam-se estudos de ampliação ou adequação de espaços para absorção de novos alunos (salas de aula) e também para a oferta de atividades demandadas pelos alunos do Ensino Médio noturno, tais como quadras esportivas e anfiteatros. Pode-se priorizar a construção desses espaços nas escolas, que por sua localização geográfica permitem o atendimento do maior número possível de jovens, como também orientar recursos para que, de forma combinada com outras secretarias, se possa ocupar espaços semelhantes, já existentes nas cidades. 


\section{Criação e desenvolvimento de programas, nos estados, que viabi- lizem o acesso à internet, por alunos e professores do Ensino Médio noturno.}

A disseminação do acesso à internet, além da aquisição de máquinas e programas, pode permitir minimizar a situação de isolamento de algumas escolas, em determinadas localidades. A precariedade de recursos disponíveis na escola, somada à velocidade e ao volume de informações em circulação, agrava ainda mais essa situação de isolamento, reduzindo as possibilidades de inserção social dos jovens e adultos atendidos pelo Ensino Médio noturno. O acesso à informação é condição para trabalhar a perspectiva de produção de conhecimento pelos alunos.

\section{Promover a organização de equipe dirigente nas escolas.}

A concentração das responsabilidades administrativas e pedagógicas em apenas uma pessoa, o diretor, faz com que este privilegie uma dessas facetas, geralmente a administrativa, negligenciando a atividade de coordenação pedagógica. A composição de equipes dirigentes que assumam suas funções a partir de um projeto comum de trabalho pode ser um importante apoio para a melhoria do Ensino Médio noturno. Isso é mais facilmente exeqüível em redes que utilizam a eleição para alocação de seus dirigentes. Por exemplo, no caso de eleições, que seja eleito um grupo de dirigentes, composto, ao menos, por um diretor geral, um diretor adjunto e um coordenador pedagógico. Em sistemas que não adotam essa prática, pode-se estabelecer essa composição nos planos de carreira. 


\section{Incentivar a avaliação do trabalho desenvolvido no Ensino Médio noturno, pelas próprias escolas, como parte do processo de avaliação institucional.}

A organização de mecanismos de avaliação, pelas próprias escolas, tendo como fonte o diagnóstico de expectativas, as opiniões e os resultados alcançados, segundo alunos, professores, pais e equipe dirigente das escolas, tem potencial de dar sustentação e subsidiar a tomada de decisões. Nessa perspectiva, o projeto político-pedagógico é, ao mesmo tempo, o organizador do trabalho na escola e o parâmetro para sua avaliação.

\section{Estimular a criação e o desenvolvimento de programas voltados à ampliação de vivências culturais para os alunos e professores do Ensino Médio noturno.}

Atividades de ampliação do repertório cultural de alunos e profissionais das escolas são demandadas e, reconhecidamente, são uma necessidade, em razão da carência de espaços que possibilitem essas vivências para todos. Projetos com esse foco, visando criar condições para a inserção crítica e criativa de jovens e adultos do Ensino Médio noturno na realidade social, devem ser incentivados. 


\section{Propor diretrizes que contemplem alternativas organizacionais diferenciadas de atendimento aos alunos do Ensino Médio noturno.}

A flexibilização curricular, visando à promoção de trajetórias escolares diferenciadas para os diferentes públicos do Ensino Médio noturno (alunos em idade regular, alunos em idade defasada, conforme os critérios estatísticos do INEP, e alunos-trabalhadores), é recomendada. Exemplos disso são: a adoção dos projetos de trabalho como organizadores do currículo, a adoção do regime de progressão continuada, a adoção de mecanismos de classificação e reclassificação, a adoção de organização modular e a alternância entre o ensino presencial e o ensino à distância, o que permitiria aos alunos perseguirem trajetórias diferenciadas, atendendo às suas disponibilidades e interesses.

\section{Impulsionar estudos e debates sobre os Referenciais Curriculares para o Ensino Médio nas escolas.}

A sustentação pedagógica para a organização, por parte das escolas, de um currículo flexível, pautado em interesses e necessidades dos alunos, pode ser apoiada na disseminação e contextualização dos Parâmetros Curriculares para o Ensino Médio. Deve ser explicitada a necessidade de que esses referenciais sejam debatidos à luz das modificações do sistema produtivo e dos processos de trabalho, das possibilidades, limitações e exigências do mercado de trabalho, do perfil do aluno do Ensino Médio noturno, dos contextos decorrentes das diversas situações geográficas e das desigualdades sociais.

\section{Identidade do Ensino Médio}

Alunos, professores e demais profissionais das escolas entendem que, no ensino médio, é necessário promover a formação geral e a formação profissional. A preparação para o vestibular é preocupação de algumas das escolas pesquisadas. Nelas verificou-se a presença de "cursinhos pré-vestibulares", paralelos ao curso, e de exames "simulados" dos vestibulares integrados à proposta do ensino. Nessas escolas, na maioria das vezes, a demanda 
pelo ensino superior entre os alunos do Ensino Médio noturno é grande. Conceber a identidade do Ensino Médio noturno com vistas à sua democratização implica ter a diversidade como princípio norteador.

\section{Conclusão}

As indicações aqui apresentadas resumidamente em alguma medida têm sido incorporadas a iniciativas do governo federal; outras permanecem como "agenda" a ser enfrentada se, de fato, pretendemos combater a profunda desigualdade existente no interior do sistema educacional brasileiro.

\section{REFERÊNCIAS}

BEISIEGEL, Celso de Rui. O Ensino Médio sob a perspectiva da educação básica. In: ZIBAS, Dagmar; AGUIAR, Márcia; BUENO, Maria Sylvia Simões. O Ensino Médio e a Reforma da Educação Básica. Brasília: Plano, 2002. p. 33-45.

BRASIL. Constituição da República Federativa do Brasil, de 5/10/1988, atualizada pelas EC 14/96 e 53/06.

BRASIL. Conselho Nacional de Educação. Diretrizes Curriculares Nacionais para o Ensino Médio. Parecer CEB n. 15/98, aprovado em 1/6/98 (Processo n. 23001.000309/97-46).

BRASIL. Decreto n. 2.208, de 17 de abril de 1997. Regulamenta o $\S 2^{\circ}$ do art. 36 e os arts. 39 a 42 da Lei n. 9.394, de 20 de dezembro de 1996. Estabelece as diretrizes e bases da educação nacional.

BRASIL. Emenda Constitucional n. 14, de 13 de setembro de 1996.

BRASIL. Lei n. 5.692, de 11 de agosto de 1971. Lei de Diretrizes e Bases da Educação Nacional.

BRASIL. Lei n. 7.044, de 18 de outubro de 1982. Altera dispositivos na Lei n. 5.692/71 referentes à profissionalização no ensino de segundo grau e dá outras providências. 
BRASIL. Lei n. 9.394, de 20 de dezembro de 1996. Estabelece as Diretrizes e Bases da Educação Nacional.

BRASIL. Lei n. 10.172, de 9 de janeiro de 2001. Aprova o Plano Nacional de Educação e dá outras providências.

CURY, Carlos Roberto Jamil. Ensino médio no Brasil: histórico e perspectivas. In: SEMINÁRIO INTERNACIONAL POLÍTICAS PÚBLICAS DO ENSINO MÉDIO. Anais... São Paulo: CONSED, 1998. p. 29-44

OLIVEIRA, Dalila Andrade. A recente expansão da educação básica no Brasil e suas conseqüências para o ensino médio noturno. In: FRIGOTTO, Gaudêncio; CIAVATTA, Maria (Org.). Ensino Médio: ciência, cultura e trabalho. Brasília: MEC, SEMTEC, 2004. p. 157-180.

OLIVEIRA, Maria José Cassiano de. Trajetórias escolares de alunos trabalhadores do ensino médio noturno: o significado da volta à escola. Dissertação (Mestrado em Educação) - Faculdade de Educação da Universidade Federal de Minas Gerais, Belo Horizonte, 1994.

SILVA, Heslley Machado. Jovem do ensino médio noturno: demandas em relação à escola. Dissertação (Mestrado em Educação) - Faculdade de Educação da Universidade Federal de Minas Gerais, Belo Horizonte, 2000.

SPOSITO, Marília Pontes. Trabalhador-estudante: um perfil do aluno do curso superior noturno. São Paulo: Loyola, 1989.

ZIBAS, D. M. L. Ser ou não ser: o debate sobre o Ensino Médio. Cadernos de Pesquisa, São Paulo, Fundação Carlos Chagas, v. 80, n. 80, p. 41-50, 1992.

Texto recebido em 10 set. 2007

Texto aprovado em 18 dez. 2007 